\title{
Evlerdeki Gizli Tehlike; Turşu Kur İçmeye Bağlı Özofagus Korozyonu
}

Hidden Danger at Home; Esophageal Corrosion Due to Ingestion of a Pickling Solution

\author{
Ahmet Ali TUNCER', Afra KARAVELIOĞLU', Altınay BAYRAKTAROĞLU', Didem BASKIN EMBLETON' \\ ${ }^{1}$ Afyon Kocatepe Üniversitesi Tıp Fakültesi, Çocuk Cerrahisi AD, Afyonkarahisar \\ Geliş Tarihi / Received: 11.04.2014 \\ Kabul Tarihi / Accepted: 20.05.2014
}

\begin{abstract}
ÖZET
Çocuklarda kostik madde içiminedeniile gelişen özofagus yanıkları ülkemiz gibi gelişmekte olan ülkelerde oldukça sık görülmektedir. Bu yazıda yerel ve ulusal firmalar tarafından üretimi olan ve halk arasında "turşu kur" ismiyle bilinen, turşu yapımında kullanılan ürünün içimine bağlı özofagus yanığı gelişen 4 yaşında kız hasta sunulmuştur. Turşu yapım solüsyonları market raflarında kolaylıkla bulunmaktadır ve bazıları içerdikleri asetik asit nedeniyle zararlı olabilirler. Diğer korozif ürünlerin aksine gıda yapımında kullanılması nedeniyle ailelerin tehlikeli görmediği bu ürünler hakkında farkındalığın artırılması amaçlanmıştır.
\end{abstract}

Anahtar Kelimeler: Özofagus; korozif içme; turşu solüsyonu; asetik asit; sitrik asit.

\begin{abstract}
Esophageal burns due to caustic substance ingestion are frequently observed in developing countries. In this report a 4-year-old girl is presented with esophageal burn due to the ingestion of the substance used to prepare pickles that produced by a local company and known as pickling solution among the people. Pickling solutions are products that can easily be found on the shelves of grocery stores and some can be harmful because they contain acetic acid. It's aimed to raise awareness about these products because unlike other corrosive products the families don't see the danger as it is used in making food.
\end{abstract}

Keywords: Esophagus; corrosive ingestion; pickling solution; acetic acid; citric acid. 


\section{Giriş̧}

Korozif maddelerin yanlışlıkla içilmesi çocukluk çağında oldukça sık görülür. Korozif maddelerin içimi ile oluşan hasar çocukluk çağında önemli bir mortalite ve morbidite sebebidir. Korozif maddeler; özofagus ve mide ile teması halinde hem histolojik hem de fonksiyonel olarak zarar veren maddelerdir. Çocukların doğal merakı ve her şeyi tatmaya olan eğilimleri, ev içindeki kimyasallara ulaşabilmeleri ile birleştiğinde özofagus yaralanmaları kaçınılmaz olmaktadır (1). Çalışmamızda yerel ve ulusal firmalar tarafından üretimi olan ve halk arasında 'turşu kur' ismiyle bilinen, turşu yapımında kullanılan ürünün içimine bağlı özofagus yanığı gelişen 4 yaşında kız hasta sunulmuştur.

\section{OLGU SUNUMU}

Turşu kur içme şikayetiyle acil servise başvuran hastanın genel durumu iyi, bilinci açık, koopere ve oryanteydi. Fizik muayenesinde; dudakları ödemli, ağız içi ve orofarenksi hiperemik ve fibrinlerle kaplıydı. Tükrüğünü yutamadığı ve tükrüğünün ağız kenarından aktığı izlendi (Şekil I). Hastaya ilk başvurduğu merkezde aktif kömür uygulandığı için lezyonların üzerinde siyah alanlar mevcuttu. Hastanın batınında hassasiyet

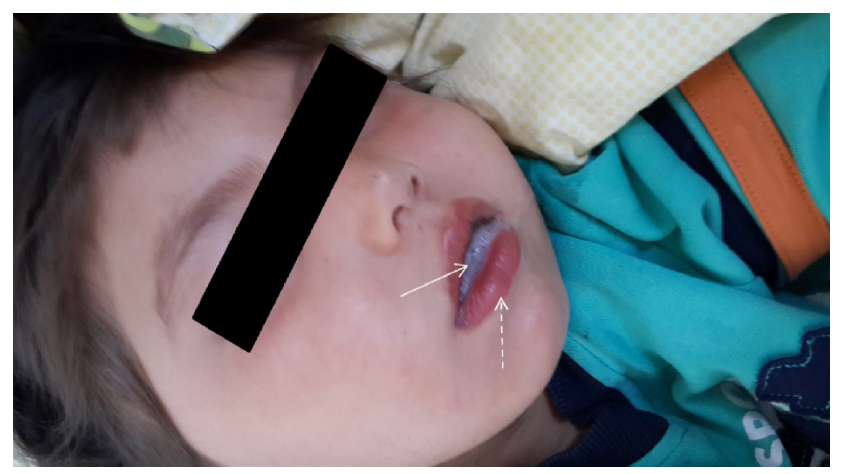

Şekil I: Fizik muayenede hastanın dudaklarının ödemli olduğu (kesik ok), tükrüğünü yutamadığı ve tükrüğün ağzından dışarı aktığı izlendi (ok)

yoktu. Akciğer grafisi normaldi. Hasta takip ve tedavisi yapılmak üzere çocuk cerrahisi servisine yatırıldı. Oral alımı kesildi. İntravenöz (IV) olarak mayi, ampisilin-sulbaktam, esomeprazol başlandı. Hastaya düzenli olarak ağız bakımı yapıldı. Yatışının 3. günü özofagoskopi yapılan hastada laringoskopla bakıldığında dil üzeri, ağız içi ve orofarenkste tüm alanların fibrinle kaplı ve erozyona uğramış olduğu görüldü
(Şekil II). Yer yer aktif kömür uygulamasına bağlı olduğu düşünülen siyah alanların bulunduğu izlendi. Özofagus girişi ödemden dolayı net

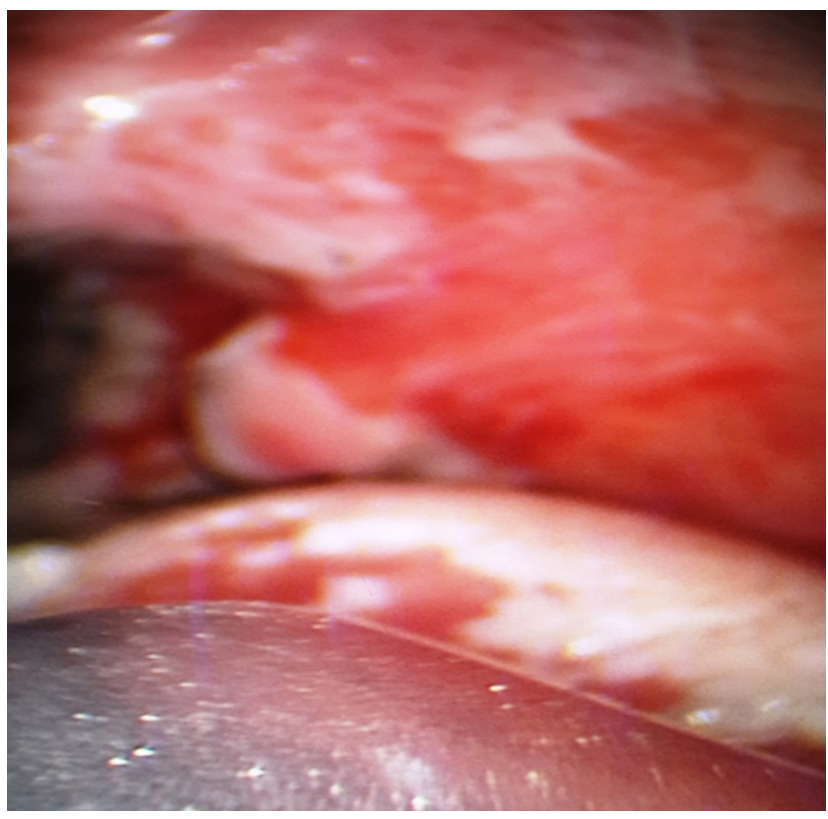

Şekil II: Özofagoskopla bakıldığında orofarenkste yer yer fibrinlerle (ok) kaplı hiperemi (kesik ok) alanları, dil üzerinde de fibrin ve hiperemi alanları izlendi (yıldız).

değerlendirilemeyince özofagoskopi işlemi sonlandırıldı. Hastanın iv antibiyoterapisine amikasin ve metronidazol eklendi. Total parenteral beslenme başlandı. Yatışının 7. günü hastanın ağız muayene bulguları gerileyince endoskopi yapıldı. Ağız içi bulgularının iyileşmiş olduğu, uvula, nazofarenksveözofagus girişinde yer yer iyileşmekte olan yanık alanları izlendi. Özofagusta yaygın yanık alanları mevcuttu ve alt uçta evre $2 b$ ile uyumlu sirküler tarzda yanık alanı izlendi. Mide normaldi. Medikal tedavisine devam edilen hastaya postoperatif 2. gün sıvı ağırlıklı diyet başlandı. Yatışının 10. gününde iv antibiyotikleri, esomeprazol ve total parenteral beslenmesi kesildi. Oral sukralfat süspansiyonu başlandı. Genel durumu iyi olan ve oral alımı düzelen hasta, yatışının 12. günü sıvı ağırlıklı diyet önerisiyle taburcu edildi. Hastanın 3 hafta sonra çekilen özofagogramında özofagusta darlık izlenmedi. Hasta 8 aydır komplikasyonsuz olarak izlenmektedir.

\section{TARTIŞMA}

Korozif özofagus yanıklarında minimal mukozal yaralanmadan, özofagus duvarında tam kat nekroza varan değişiklikler meydana gelir. 
Alkali korozif maddeler likefaksiyon nekrozu, asit içerikli maddeler koagülasyon nekrozu oluşturur. Alkali maddeler daha çok özofagusta hasarlanma yaparken, asidik maddeler daha çok midede hasarlanma yaparlar (2). Evlerde kullanılan çamaşır suyu, bulaşık deterjanları gibi temizleyici maddeler orta derecede alkali olan ve sıklıkla içilen korozif maddelerdir. Bu maddeler ile oluşan yaralanmalar genellikle özofageal mukoza ile sınırlıdır, ciddi nekroz ve striktür oluşturmazlar. Güçlü asitler yutulursa özellikle mide antrumunda hasara neden olurlar.

Sirke veya turşu kur üretiminde kullanılan kostik maddelerden birisi olan asetik asitin \%75'lik çözeltisi sirke ruhu olarak adlandırılmakta ve korozif etkileri literatürde vaka serileri içerisinde birkaç vaka ile sınırlı olarak bulunmaktadır $(1,3)$. Turşu kur içilmesinin korozif etkileriyle ilgili ise herhangi bir yayına ulaşılamamıştır.

Asetik asit $\mathrm{CH} 3 \mathrm{COOH}$ formüllü bir organik asittir, sirkeye ekşi tadını ve keskin kokusunu vermesiyle bilinir. Doğada karbonhidratların yükseltgenmesiyle oluşur. Sanayide asetik asit hem biyolojik yolla hem de sentetik yolla imal edilir. Suda tamamen çözünür. Sirke \%5 oranında asetik asit içerir ama turşu kurmak için kullanılan sirkelerde bu oran \%18'e ulaşabilir $(4,5)$. Sirkenin oluşturduğu asitli ortam gıdaların bozulmasına neden olacak çoğu mikroorganizmanın büyümesini engeller. Bu yüzden turşulama, sebzelerin ömrünü uzatmak için etkili bir yöntemdir. Asetik asitten sanayide çok faklı alanlarda yararlanılmaktadır. Tahta tutkalı hammaddesi, kimyasal çözücü, dokuma sanayinde ve gıda katkı maddesi olarak (E262), fotoğraf filmi üretiminde, ev içinde temizlik amacıyla, çaydanlıkların kireçten arındırılmasında, parlak yüzeylerdeki madenî birikmeleri temizlemekte ve sirke üretiminde kullanılmaktadır (4). Yoğun asetik asitin (>\%25), keskin kokusu ve yakıcı buharından dolayı kullanımı sadece laboratuvarla sınırlandırılmıştır. Seyreltik asetik asit (sirke gibi) zararsızdır, ama daha kuvvetli çözeltileri insan ve hayvanlar için zararlıdır (4).
Konsantre asetik asitin cilt, solunum yolları ve üst gastrointestinal sistemde lokal olarak korozif etkilere sebep olduğu bilinmektedir (5). Sistemik etkileri ise; solunum yetmezliği, dissemine intravasküler koagülasyon (DiK), metabolik asidoz, hemoliz ve bunu takip eden hemoglobinüri nedeniyle oluşan böbrek yetmezliği olarak sıralanabilir $(5,6)$. Kamijo ve arkadaşları \%90 konsantrasyonda $200 \mathrm{ml}$ asetik asit içimi sonrası exitus olan hastaya yaptıkları otopside 45 dakika içerisinde karaciğerde ciddi non-inflamatuar periportal nekroz alanları izlemişlerdir (7). Hayvan çalışmalarında \%10'luk konsantrasyonda asetik asitin kalıcı görme kaybına neden olduğu gösterilmiştir. Amerika Tüketici Koruma Güvenlik Komisyonu asetik asitin \%10'luk konsantrasyonunun ciltte abrazyonlara sebep olabileceğini, \%20 'nin üzerindeki konsantrasyonlarda çözeltinin oral alımının ise ölümcül seyredebileceğini bildirmiştir (5). Bizim hastamızda herhangi bir sistemik etki izlenmedi.

Turşu üretiminde asitlik düzenleyici olarak kullanılan bir diğer madde olan sitrik asit ise halk arasında limon tuzu olarak da bilinir. Renksiz, kristal yapılı, organik bir bileşiktir. Formülü C6H8O7 şeklindedir. Hemen hemen tüm bitkilerde ve birçok hayvanın vücut sıvısında bulunur. pH değeri 3.5'tir. Metal temizleme işlerinde, gıdaların ve çeşitli organik maddelerin dayanıklıı̆̆ını arttırmak için ve bazı alkolsüz içeceklere tat vermek için kullanılır. Şekerleme ve ilaç yapımında da yararlanılır. Özellikle turunçgillerde büyük miktarlarda bulunur (8). Sitrik asitin korozif etkili olup olmadığıyla ilgili literatürde herhangi bir çalışma bulunamamıştır. 114 Ulusal Zehir Danışma Merkezi (UZEM) kaynaklarında sitrik asitin orta dereceli asit özelliğinde, allerjen ve irritan madde olarak yer aldığı ve içilmesi durumunda metabolik asidoz, hiperkalemi, hipotansiyon ve taşikardi gelişebileceği bildirilmektedir. Korozif etkisi ile ilgili bilgi yoktur (9).

Afyonkarahisar ilinde yapmış olduğumuz araştırma sonucu turşu kur ismiyle marketlerde satılan 5 ürüne ulaşılmıştır. Bu ürünlerden 2'si 
yerel olarak Afyon firmaları tarafından üretilen, 3'ü de ulusal firmalar tarafından üretilip hipermarketlerde satışa sunulan ürünlerden oluşmaktaydı (Tablo I). Ulusal ürünlerden sıvı bazlı olarak hazır bulunan A ve B ürünü herhangi bir sulandırılmaya gerek kalmadan direk olarak turşu yapımında kullanılırken, bu ürünlerde üzüm sirkesi ve sitrik asit kullanılmaktadır. Ulusal ürünlerde $C$ kodlu olan ürün ise toz olarak $100 \mathrm{gr}$ 'lık paketlerde satılmakta, sitrik asit içermekte ve $750 \mathrm{ml}$ su ve $300 \mathrm{ml}$ üzüm sirkesi ilave edilerek kullanılmaktadır. Yerel firmalar tarafından üretilen ürünlerde ise asetik asit bulunmakta ve 1,4 L lik sıvı çözeltisi $10 \mathrm{~L}$ su ile sulandırılarak kullanılmaktadır. TC. Gıda Tarım ve Hayvancılık Bakanlığının hazır gıdalara konulan katkı maddeleriyle ilgili gıda katkı maddeleri ve etiketleme yönetmelikleri bulunmaktadır. Ancak bu yönetmeliklerde direk olarak "turşu kur" içeriği ile ilgili maddeler bulunmamaktadır.

Tablo I: Afyonkarahisar'da marketlerde bulunan hazır turşu kur preparatlarının özellikleri

\begin{tabular}{|c|c|c|c|c|}
\hline Ürün kodu & \begin{tabular}{|c|}
$\begin{array}{c}\text { Ürün dağıtım ağı } \\
\text { Yerel /Ulusal }\end{array}$ \\
\end{tabular} & $\begin{array}{c}\text { Ürün formu } \\
\text { Sıvı/toz- ağırlık }\end{array}$ & İçindekiler & $\begin{array}{c}\text { Konsantrasyon } \\
\text { Oranı }\end{array}$ \\
\hline A & Ulusal & SIVI-3 L & $\begin{array}{l}\text { Tuz, üzüm sirkesi, } \\
\text { sitrik asit, kalsiyum } \\
\text { klorür, potasyum } \\
\text { sorbat, sodyum } \\
\text { metabisülfit, askor- } \\
\text { bik asit, karamel }\end{array}$ & $\begin{array}{l}\text { 2,5 kg sebzeye } \\
\text { direkt olarak uy- } \\
\text { gulanır. }\end{array}$ \\
\hline B & Ulusal & SIVI-3 L & $\begin{array}{l}\text { Su, üzüm sirkesi, } \\
\text { tuz, stabilizatör } \\
\text { kalsiyum klorür, } \\
\text { koruyucu sodyum } \\
\text { benzoat, asitlik } \\
\text { düzenleyici sitrik } \\
\text { asit, antioksidan } \\
\text { sodyum metabi- } \\
\text { sülfit }\end{array}$ & $\begin{array}{l}\text { 2,5 kg sebzeye } \\
\text { direkt olarak uy- } \\
\text { gulanır. }\end{array}$ \\
\hline C & Ulusal & Toz-100 gr & $\begin{array}{l}\text { İi salamura tuzu, } \\
\text { asitlik düzenleyici } \\
\text { sitrik asit, taşıııcı } \\
\text { kalsiyum klorür, acı } \\
\text { toz kırmızı biber, } \\
\text { toz glukoz, tane } \\
\text { baharat (karabiber, } \\
\text { hardal), koruyucu } \\
\text { sodyum benzoat, } \\
\text { sarımsak konsant- } \\
\text { resi, kurutulmuş } \\
\text { defne ve kereviz } \\
\text { yaprağı, aroma }\end{array}$ & $\begin{array}{l}\text { 0,5-1 kg sebze- } \\
\text { ye } 750 \mathrm{ml} \text { su ile } \\
\text { sulandırılıp } 300 \mathrm{ml} \\
\text { sirke ilave edilerek } \\
\text { uygulanır. }\end{array}$ \\
\hline D & Yerel & SIVI-1,4 L & $\begin{array}{l}\text { Su, tuz, asitlik } \\
\text { düzenleyici (asetik } \\
\text { asit), antimikro- } \\
\text { biyal (sodyum } \\
\text { benzoat) }\end{array}$ & $\begin{array}{l}10 \text { kg sebzeye } 10 \\
\text { L suyla sulandırıla- } \\
\text { rak uygulanır. }\end{array}$ \\
\hline $\mathbf{E}$ & Yerel & SIVI-1,4 L & $\begin{array}{l}\text { Su, tuz, asitlik } \\
\text { düzenleyici (asetik } \\
\text { asit), antimikro- } \\
\text { biyal (sodyum } \\
\text { benzoat) }\end{array}$ & $\begin{array}{l}10 \mathrm{~kg} \text { sebzeye } 10 \\
\mathrm{~L} \text { suyla sulandırıla- } \\
\text { rak uygulanır. }\end{array}$ \\
\hline
\end{tabular}


Hangi katkı maddelerinin ne tür gıdaların üretiminde ve ne oranda kullanılabileceği belirtilmemektedir (10). Bizim market raflarında ulaştığımız 5 ürünün hiç birisinde içerdikleri maddelerin miktar ve oranlarına dair bir bilgiye rastlanılmadı. Özellikle yerel firmaların üretimini yaptığı turşu kur ürünlerinde asetik asit kullanılmakta, ancak hangi oranda kullanıldığı belirtilmemektedir. Ayrıca bu ürünlerin 1,4/10 oranında sulandırılarak kullanıldığını düşünürsekkonsantrehaldekiçözeltininiçilmesi durumunda daha tehlikeli sonuçların ortaya çıkabileceği öngörülebilir. Bizim olgumuzda da yerel bir firma tarafından üretilen turşu kur isimli ürünün özofagusta korozyonlara sebep olması bu durumla örtüşmektedir.

Sonuç olarak turşu kurun markalı ya da markasız formları marketlerden kolaylıkla temin edilebilmektedir. Bu ürünler değişik oranlarda içerdikleri, derişik asetik asit nedeniyle zararlı olabilmektedir. Korozif madde içilmesini önlemenin en kolay yolu bu tür maddelerin kilitli kapak sistemiyle üretilmesi ve evlerde çocukların ulaşamayacakları kilitli raflarda saklamaktan geçmektedir. Ancak turşu kur diğer korozif ürünlerin aksine gıda yapımında kullanılması nedeniyle ailelerin tehlikeli görmediği bir ürün durumundadır. Bu ürünün çocuklar tarafından içildiğinde içerdiği asetik asit nedeniyle ölümcül komplikasyonlara sebep olabileceği bilinmeli ve çocukların ulaşamayacakları şekilde muhafaza edilmeleri sağlanmalıdır. Ayrıca Sağlık Bakanlığı, Gıda Tarım ve Hayvancılık Bakanlığı gibi ilgili bakanlıkların dikkati çekilmeli ve bu tür malzemelerin üretilmesi, etiketlenmesi, dağıtılması ve kullanılmasında yeni düzenlemelerin yapılması sağlanmalıdır.

\section{KAYNAKLAR}

1.Ceylan Ö. Koroziv madde içen süt çocuklarında sosyal demografik ve endoskopik bulguların değerlendirilmesi. Uzmanlık Tezi. İstanbul: TC Sağlık Bakanlığı Şişli Etfal Eğitim ve Araştırma Hastanesi, Çocuk Sağlığı ve Hastalıkları Anabilim Dalı, 2008;12.
2. Chandler N, Colombani PM. The esophagus. In: Holcomb GW, Murphy JP. Ashcraft's pediatric surgery 5. Ed, Philadelphia: Saunders Elsevier, 2010:330-44.

3. Karaoğlu AÖ, Özütemiz Ö, İlter T, et al. Akut koroziv özofajit:108 olgunun değerlendirilmesi. Turk J Gastroenterol 1998;1(1):55-60.

4.http://en.wikipedia.org/w/index.php?title=Acetic_ acid\&oldid=134416361 Erişim 03.04.2014

5. Hsu TK, Jaun CV, Huang CC. Acute oral acetic acid intoxication: a case report. J Emerg Crit Care Med 2009;20(3):145-50.

6. Jurim O, Gross E, Nates J, Eldor A. Disseminated intravascular coagulopathy caused by acetic acid ingestion. Acta Haematol 1993;89(4):2045.

7. Kamijo Y, Soma K, Iwabuchi K, Ohwada T. Massive noninflammatory periportal liver necrosis following concentrated acetic acid ingestion. Archives of Pathology \& Laboratory Medicine 2000;124(1):127-9.

8.http://tr.wikipedia.org/w/index.php?title=Sitrik asit\&action=edit\&section=3 Erişim 03.04.2014

9. MicroMedex (R) healthcare series, volume 159 expires///2014.

10.http://www.tarim.gov.tr/GKGM/Documents/ Genel/Mevzuat/gida_katki_maddeleri_yonetmelik_ eklerii.zip Erişim 03.04.2014 